\title{
ONCOCYTOMA OF PAROTID GLAND
}

Prem Charles ${ }^{1}$, P. Narmadha르, P. Viswanathan ${ }^{3}$, U. Manohar ${ }^{4}$, Paramasivam ${ }^{5}$

\section{HOW TO CITE THIS ARTICLE:}

Prem Charles, P. Narmadha, P. Viswanathan, U. Manohar, Paramasivam. "Oncocytoma of Parotid Gland". Journal of Evolution of Medical and Dental Sciences 2014; Vol. 3, Issue 35, August 14; Page: 9366-9370,

DOI: $10.14260 /$ jemds/2014/3207

ABSTRACT: Oncocytomas are rare benign epithelial neoplasms composed of oncocytes, which are large cells with granular eosinophilic cytoplasm containing excessive and atypical mitochondria. We report a case of oncocytoma of parotid salivary gland which constitutes between zero and three percent of salivary gland neoplasms.

KEYWORDS: Oncocytes, parotid gland.

INTRODUCTION: Identified criteria for salivary gland oncocytes include:

1. Appearance after maturity of the salivary gland;

2. A high level of oxidative activity;

3. An unusually large number of mitochondria; and

4. Absence of specialized features of normal cells, such as brush borders and basal enfolding. An estimated sixty percent of the cytoplasmic volume was occupied by mitochondria in salivary gland oncocytes.

CASE HISTORY: A39 year old female was presented with a swelling over the left parotid region for about ten months duration. The swelling measures about $4 \times 3 \mathrm{~cm}$ in size, non-tender, firm in consistency lifting the tragus of the left ear lobe. The swelling was excised and sent for histopathological examination.

Macroscopically, a single grey brown swelling measures about $3 \times 3 \mathrm{~cm}$ in dimension. On cut surface a well circumscribed grey white areas are identified.

On microscopic examination, parotid salivary gland with its serous acini (FIG: 2) was noticed; adjacent to it are closely packed polyhedral shaped oncocytes with abundant eosinophilic granular cytoplasm with central nuclei (FIG: 1) was observed. The oncocytes are arranged in trabeculae resembling Hepatoid appearance (FIG: 1).With above histological features the diagnosis of Oncocytoma of parotid gland was made out.

DISCUSSION: Oncocytic cells had been identified in many organs but most frequently in salivary gland, thyroid gland, parathyroid, pulmonary tree, and kidney. ${ }^{1}$

The occurrence of oncocytic cells in salivary glands can be categorized as oncocytic metaplasia, nodular or diffuse oncocytosis, and oncocytoma.

Oncocytic metaplasia was the transformation of ductal and acinar epithelium to oncocytes. Oncocytic metaplasia most frequently observed in mixed tumors and mucoepidermoid carcinomas of salivary gland.

Oncocytosis was the accumulation and proliferation of oncocytes in the salivary glands. These may be diffuse involving the entire gland parenchyma ${ }^{2}$ or producing microscopic and macroscopic nodules which was termed as nodular oncocytic hyperplasia or nodular oncocytosis. ${ }^{3}$ 
Oncocytoma was a nodule of oncocytes that was clinically detectable, circumscribed and demarcated from surrounding salivary gland parenchyma by an incomplete fibrous capsule and was significantly larger than other nodules of oncocytic cells that are present in the gland.

Oncocytomas constitute between zero and three percent of salivary gland neoplasms; the average was just under one percent. ${ }^{4}$ At the AFIP since 1985, oncocytomas comprised about two percent of all salivary gland epithelial neoplasms. The parotid gland was the predominant site of occurrence $^{5}$ and oncocytomas in the minor salivary gland are rare. ${ }^{6}$

Among seventy two recent oncocytomas in the AFIP files two were from intraoral salivary glands. Oncocytomas are rare in patients younger than fifty years: less than six percent of the oncocytomas in the AFIP files since 1985 occurred in patients less than fifty years old. The peak incidence was in the seventh to ninth decades of life. ${ }^{7}$ Many investigators had reported an equal predilection for men and women, ${ }^{8}$ although the data of the AFIP and others indicate a slight female preponderance among patients. ${ }^{9}$

An increased incidence of salivary gland neoplasms had been associated with exposure of head and neck region to ionizing radiation. ${ }^{10}$ These oncocytomas occurred, on average, in much younger patients than those without a history of radiation exposure.

Swelling was the only common complaint of patients in all cases of oncocytoma; rarely pain was associated with these tumors. The duration of tumor before surgery was few weeks to twenty years, but less than two years was typical. ${ }^{2}$ The swellings are single or multiple nodules. Brandwein and Huvos ${ }^{5}$ estimated that bilateral parotid gland or submandibular gland disease, synchronous or metachronous, occurs in at least seven percent of patients.

Grossly the tumor was single, encapsulated or well circumscribed; tan to red brown nodule was evident. Occasionally one or more cysts are present within the tumor nodules. The tumor range in size from one to seven centimeter, but three to four centimeter was typical.

With light microscopy the oncocytes are large polygonal cells with prominent, granular eosinophilic cytoplasm and centrally placed nuclei with dispersed chromatin and single nucleoli. The intensity of cytoplasmic staining was variable, darker and lighter cells were also identified. Ultrastructurally, the most conspicuous feature was abundant cytoplasmic mitochondria. The oncocytes in oncocytomas are arranged in an organoid pattern of tightly packed clusters that are separated and surrounded by thin, inconspicuous capillaries and strands of fibrovascular stroma.

Small lumens are often apparent in the centers of the clusters. In other tumors, the oncocytes are arranged in short serpentine cords in a hepatic-like arrangement. Microcysts or macrocysts transformation with an associated lymphoid infiltrate resembling Warthin's tumor may also be identified.

Oncocyte are cells with prominent eosinophilic cytoplasm, but paradoxically clear cells dominate particularly in multinodular oncocytic hyperplasia. Clear cell oncocytomas have the same organoid pattern; the clear cytoplasm was due to the accumulation of glycogen in the oncocytes noted to be PAS positive. In addition to electron microscopic evidence of mitochondrial proliferation was helpful in diagnosis; in addition to that, Phosphotungstic Acid Hematoxylin staining was often useful in identifying oncocytes.

DIIFERENTIAL DIAGNOSIS: Mixed tumor and mucoepidermoid carcinoma are the two salivary gland neoplasms that most frequently demonstrate oncocytic metaplasia. Oncocytomas lack the 
pleomorphic patterns, chondromyxoid tissue and proliferation non-cohesive myoepithelial type cells that typify mixed tumors. Mucous cell differentiation, demonstrated with mucicarmine stain for diagnosis of mucoepidermoid carcinoma, rare in oncocytoma. Clear cell neoplasms like clear cell mucoepidermoid carcinoma, clear cell adenocarcinoma, epithelial-myoepithelial carcinoma, clear cell acinic cell adenocarcinoma and the metastatic renal cell carcinoma are other differential diagnosis to be considered.

Reported recurrence rates for oncocytomas ranged from zero to thirty percent. ${ }^{11}$ Multifocal tumor growth and incomplete excision appear to be factors in the incidence of recurrence. Excision was the principal mode of therapy for primary and recurrent tumors. Radiation had been used in some cases. ${ }^{8}$ Kosuda et al ${ }^{12}$ recommended radioiodine therapy after finding reduction in tumor volume of an oncytoma in a patient treated with therapeutic dose of Iodine- 131.

The patient was on constant follow up and was found to be free from tumor. He was advised for regular follow up life-long.

\section{REFERENCES:}

1. Chaudhry AP, Labay GR, Yamane GM, Jacobs MS. Cutler LS, Watkins KV. Clinico pathologic and histogenetic study of 189 intraoral minor salivary gland tumors. J Oral Med 1984; 39: 58-78.

2. Palmer TJ, Gleeson MJ, Everson JW, Cawson RA. Oncocytic adenomas and oncocytic hyperplasia of salivary glands: a clinicopathological study of 26 cases. Histopathology 1390; 16: 487-93.

3. Hartwick RW, Batsakis JG. Non warthins tumor oncocytic lesions. Ann Otol Rhinol Laryngol 1990; 99: 674-7.

4. Eveson JW, Cawson RA. Salivary gland tumors: A review of 2410 cases with particular reference of histological types, site, age and sex distribution. J Pathol 1985; 146:51-8.

5. Brandwein MS. Huvos AG. Oncocytic tumors of major salivary glands. A study of 68 cases with follow up of 44 patients. Am J Surg Pathol 1991; 15: 514-28.

6. Waldron CA, el-Mofty SK, Gnepp DR. Tumors of the intraoral minor salivary glands: a demographic and histologic study of 426 cases. Oral Surg Oral Med Oral Pathol 1988; 66:32333.

7. Gray SR, Cornog JL Jr, Seo IS. Oncocytic neoplasms of salivary glands: a report of fifteen cases including two malignant oncocytomas. Cancer 1976; 38: 1306-17.

8. Blank C, Eneroth CM, Jakobsson PA. Oncocytoma of the parotid gland: neoplasm or nodular hyperplasia, . Cancer 1970; 25: 919-25.

9. Chang A, Harawi SJ. Oncocytes, oncocytosis, and oncocytic tumors. Pathol Annu 1992; 27 [Pt 1]: 263-304.

10. Palmer JA, Mustard RA, Simpson WJ. Irradiation as an etiologic factor in tumors of the thyroid and salivary gland. Can J Surg 1980; 23: 39-42.

11. Damm DD, White DK, Geissler RH Jr, Drummond JF, Henry BB. Benign solid oncocytoma of intraoral minor salivary glands. Oral Surg Oral Med Oral Pathol 1989; 67: 84-6.

12. Kosuda S, Ishikawa M, Tamura K, Mukai M, Kubo A, Hashimoto S. Iodine-131 therapy for parotid oncocytoma. J Nucl Med 1988; 29; 1126-9. 


\section{CASE REPORT}

\section{MICROSCOPIC PICTURES: H \& E SECTIONS}

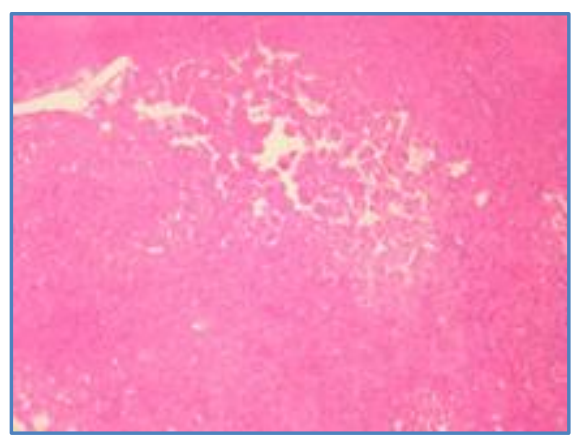

FIG. 1: 10X - Tumor composed of closely packed polyhedral cells with abundant eosinophilic cytoplasm, resembling hepatoid appearance with prominent small dark nuclei.

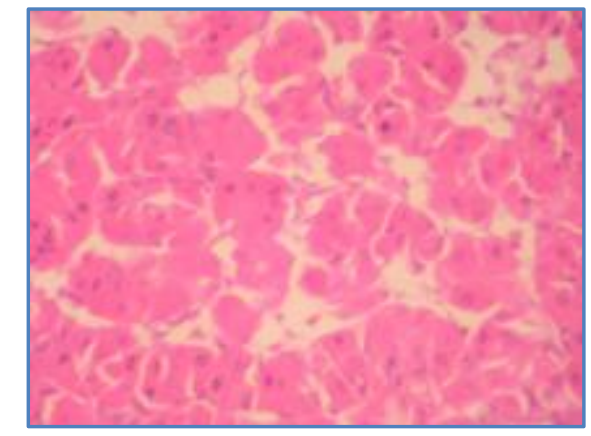

FIG. 1: 40X-Cells are arranged in trabecular pattern

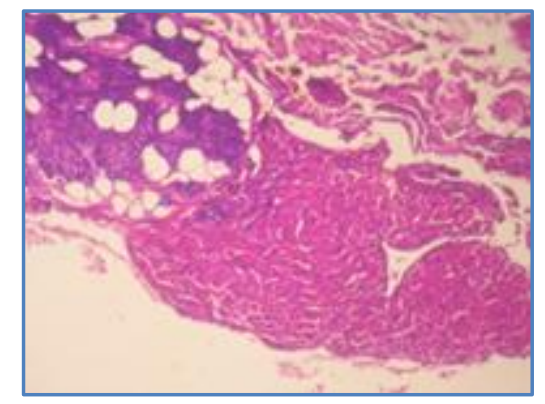

FIG. 2: 4X-Parotid salivary gland adjacent to the tumor

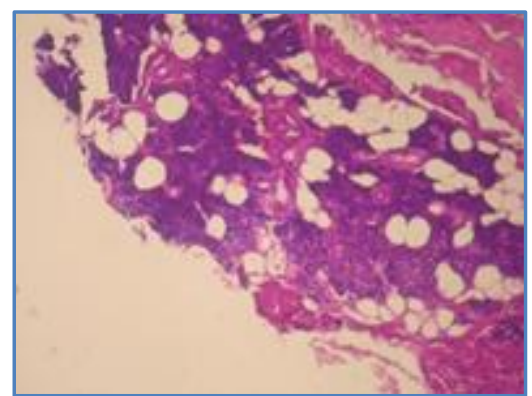

FIG. 2: 10X-Parotid salivary gland adjacent to the tumor

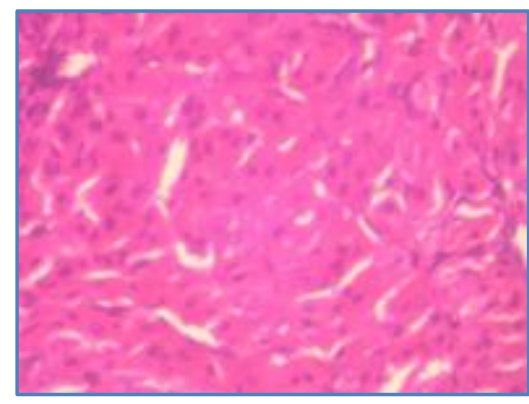

FIG. 2: 40X- Tumor is composed of closely packed cells 


\section{CASE REPORT}

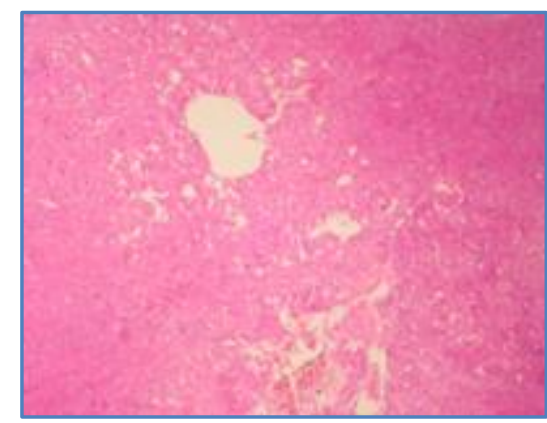

FIG. 3: 10X- Duct sorrounded

by oncocytic cells

\section{AUTHORS:}

1. Prem Charles

2. P. Narmadha

3. P. Viswanathan

4. U. Manohar

5. Paramasivam

\section{PARTICULARS OF CONTRIBUTORS:}

1. $3^{\text {rd }}$ Year Post Graduate, Department of Pathology, Rajah Muthiah Medical College, Annamalai University.

2. $3^{\text {rd }}$ Year Post Graduate, Department of Pathology, Rajah Muthiah Medical College, Annamalai University.

3. Professor and HOD, Department of Pathology, Rajah Muthiah Medical College, Annamalai University.

4. Professor, Department of Pathology, Rajah Muthiah Medical College, Annamalai University.

5. General Surgeon, Department of Pathology, S. P. Hospital, Kumbakonam.

\section{NAME ADDRESS EMAIL ID OF THE CORRESPONDING AUTHOR:}

Dr. P. Viswanathan,

Professor and HOD,

Department of Pathology,

Faculty of Medicine,

Rajah Muthiah Medical College,

Annamalai University,

Chidambaram-608002,

Tamilnadu, India.

Email: drpviswanathan2013@gmail.com

Date of Submission: 30/07/2014.

Date of Peer Review: 31/07/2014.

Date of Acceptance: 07/08/2014.

Date of Publishing: 14/08/2014. 